\title{
Application of Nanobiomaterials in Endodontics
}

\author{
Kazemipoor Maryam * \\ Department of Endodontics, Shahid Sadoughi University of Medical Sciences, Iran
}

Received: November 17, 2017; Published: December 05, 2017

*Corresponding author: Kazemipoor Maryam, Assistant Professor, Department of Endodontics, School of dentistry, Shahid Sadoughi University of Medical Sciences, Yazd, Iran, Tel: 98912 4682952; Fax: 98351 6250344; Email: dr.kazemipoor@gmail.com

\begin{abstract}
Nowadays, the application of Nanobiomaterials in dentistry is increasing. The combination of biomaterials with nanotechnology leads to the term of "Nano biomaterial". Nanotechnology aims to control over material properties at nanoscale and over the precision and sensitivity of various tools and devices in different technologies. In the endodontic science, Nanobiomaterials are utilized in different aspects such as: instruments and materials modifications, improvement of root canal disinfection and obturation, root repair materials, local anesthesia and repair and regeneration of pulpal tissue. The aim of the present study was to reviews the research findings and future possible applications of Nanobiomaterials and nanotechnology in endodontics.
\end{abstract}

Keywords: Endodontic; Nanomaterial; Nanotechnology

\section{Introduction}

Dental pulp is a unique low compliance tissue with specific characters different from similar loose connective tissues. Its encasement within the relatively rigid and unyielding dentinal walls, its particular rich neurovascular supply, a powerful immune response and scarcity of collateral circulation may lead to rapid degeneration and necrosis [1]. Dental caries, traumatic injuries and iatrogenic procedures could affect the health of dental pulp and trigger immune response within the pulpo-dentin complex $[2,3]$. Bacterial byproducts and products from the dissolution of the organic and inorganic constituents of dentin, mechanical and thermal injuries during cavity preparation, toxicity of restorative materials and more importantly micro leakage at the interface of dentinal walls and restorative materials could alter the existent balance within the pulp and cause irreversible pulpitis and pulp necrosis $[4,5]$.

Clinical endodontics is mainly directed towards curing or preventing apical periodontitis. The microbial infection of the pulp via their toxins and noxious metabolic byproducts, in addition to the presence of disintegrated pulpal tissue are the primary causes of apical periodontitis [6]. Nonsurgical root canal treatment has a high degree of predictability with favorable outcome rates of up to $95 \%$ for the treatment of teeth with irreversible pulpitis [7] and up to $85 \%$ for necrotic teeth [8]. Endodontic treatment is based on the main two integrated phases: cleansing and shaping [9]. Cleansing and shaping procedures are directed towards the mechanically debridement, disinfecting the root canal system with irrigants and medicaments, and finally optimized canal geometrics for adequate obturation and seal $[10,11]$. The mechanical debridement is aimed to prepare all the root canal surfaces in a fully incorporated form into the original canal shape. Moreover, preparation errors such as perforations, zips, transport and etc. should be absent and as much as radicular dentin should be left to avoid vertical root fracture $[12,13]$.

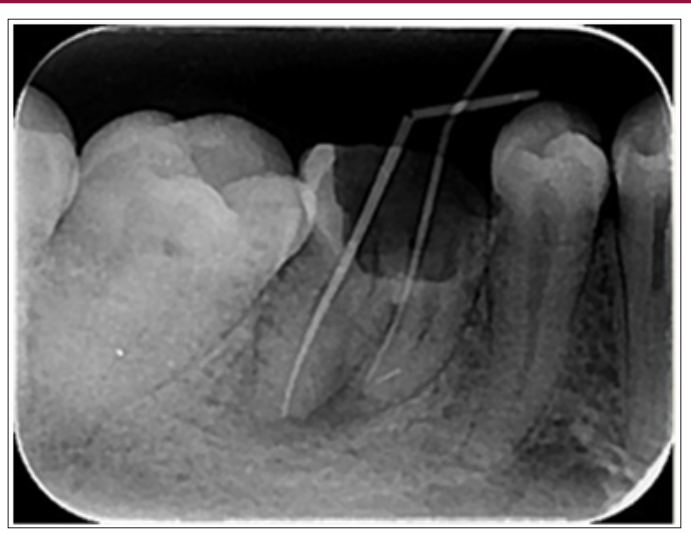

Figure 1: A separated nickel-titanium instrument in the mesiobuccal canal of mandibular first molar.

Endodontic instruments, both hand- held and engine-driven, are available for root canal preparation. Since the early 1990s, with the advent of nickel-titanium, various instrument designs and modalities have been produced in this regard [14]. Surface quality is an important factor in the function and durability of NiTi 
instruments and superficial defects such as metal flash, roll over and cracks may lead to the instrument fracture [15] (Figure1). Electro polishing the surface and coating it with titanium nitride have been recommended for promotion of the surface quality $[16,17]$. Currently, nanomaterials, with a smaller size, are being suggested for surface modification and reduction the incidence of failure in the rotary nickel-titanium files [18].

Since chemical disinfection has an important effect on a successful root canal treatment, intracanal medicaments and irrigants are necessary adjuncts that could affect the treatment outcome [19]. Nanoparticles, due to their size, have the ability of rapid dispersion into the hard-to-reach spaces in the complex root canal system which leads to a better antimicrobial effect [20]. After preparation of the root canal system, achievement of a "hermetic seal" is a major goal of root canal treatment. Various endodontic materials, including core materials and sealers, have been introduced for obturation of the radicular space [21]. Currently, no obturating material has the ideal properties outlined by Grossman [22]. The incorporation of nanoparticles in the obturating materials may enhance the sealing properties and antimicrobial efficacy [23].

Nanoscaffolds for pulp regeneration, bioceramics for retrofilling, and repair materials are other applications of nanotechnology in the endodontic treatment (Figure 2). Nanorobots and nanoterminators are also new technologies for local anesthesia with fewer side effects and complications [24]. Nanotechnology has revolutionized all aspects of science and endodontic is no exception. Nano sized particles with significantly superior properties compared to the similar materials at larges scales of measurement have improved the quality of treatment. Understanding of dental tissue at the nanoscale, enabling the precise design of materials and instruments with ultrafine architecture and improving the present techniques in clinical dentistry have significantly promoted the quality of treatment.

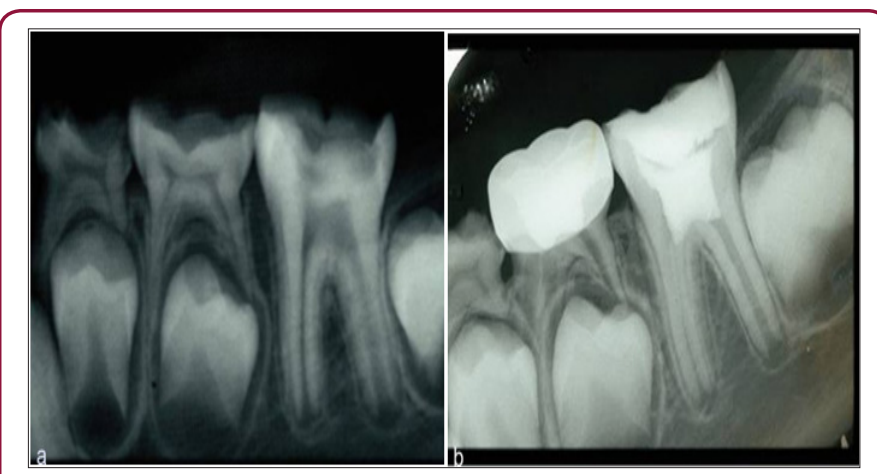

Figure 2: Deep pulpotomy for apexogenesis. a. Extensive carious exposure in an immature mandibular first molar with a history of spontaneous pain. b. After complete caries removal and hemostasis, the radicular pulp is overlaid with mineral trioxide aggregate (MTA).

Two concerns remain in this regard:

a) Nanotechnology should make its way from laboratories to clinical practice.

b) The significant potential for misuse and abuse of this technology on a scale and scope should not be overlooked.

\section{References}

1. Heyeraas KJ (1989) Pulpal hemodynamics and interstitial fluid pressure: balance of transmicrovascular fluid transport. J Endod 15(10): 468-472.

2. Smith AJ, Scheven BA, Takahashi Y, Ferracane JL, Shelton RM, et al (2012) Dentine as a bioactive extracellular matrix. Arch Oral Biol 57(2): 109-121.

3. Murray PE, Lumley PJ, Hafez AA, COX CF, Smith AJ (2002) Preserving the vital pulp in operative dentistry: 4 . Factors influencing successful pulp capping. Dent Update 29(5): 225-233.

4. Cavalcanti BN, Lage-marques JL, Rode SM (2003) Pulpal temperature increases with Er:YAG laser and high-speed handpieces. J Prosthet Dent 90: 447-451.

5. Murray PE, Smyth TW, About I, Remusat R, Franquin JC (2002) the effect of etching on bacterial microleakage of an adhesive composite restoration. J Dent 30(1): 29-36

6. Kakehashi S, Stanley H, Fitzgerald R (1965) the effects of surgical exposures of dental pulps in germ-free and conventional laboratory rats. Oral Surgery, Oral Medicine, Oral Pathology 20: 340-349.

7. Friedman S (2002) Prognosis of initial endodontic therapy. Endod Top 2: 59-88.

8. Chugal NM, Clive JM, Spangberg LS (2003) Endodontic infection: some biologic and treatment factors associated with outcome. Oral Surg Oral Med Oral Pathol Oral Radiol Endod 96(1): 81-90.

9. Tabrizizadeh M, Kazemipoor M, HekmatI-Moghadam SH, Hakimian R (2014) Impact of root canal preparation size and taper on coronal-apical micro-leakage using glucose penetration method. J Clin Exper Dent 6(4): 344-349.

10. Peters OA (2004) Current challenges and concepts in the preparation of root canal systems: a review. J Endod 30(8): 559-567.

11. Haapasalo M, Endal U, Zandi H, Coil JM (2005) Eradication of endodontic infection by instrumentation and irrigation solutions. Endod Top 10: 77102.

12. Peters OA, Laib A, Gohring TN, Barbakow F (2001) Changes in root canal geometry after preparation assessed by high-resolution computed tomography. J Endod 27(1): 1-6.

13. Lim SS, Stock CJ (1987) the risk of perforation in the curved canal: anticurvature filing compared with the stepback technique. Int Endod J 20(1): 33-39.

14. Serene T, Adams J, Saxena A (1995) Nickel-Titanium Instruments: Applications in endodontics. St. Louis Ishiyaku Euro America.

15. Alapati SB, Brantley WA, Svec TA, Powers JM, Mitchell JC (2003) Scanning electron microscope observations of new and used nickel-titanium rotary files. J Endod 29(10): 667-669.

16. Rapisarda E, Bonaccorso A, Tripi TR, Fragalk I, Condorelli GG (2000) the effect of surface treatments of nickel-titanium files on wear and cutting efficiency. Oral Surg Oral Med Oral Pathol Oral Radiol Endod 89(3): 363368.

17. Chogle SMA, Kinaia BM, Goodis HE (2013) Scope of Nanotechnology in Endodontics. In: Subramani K, Ahmed W, Hartsfield JK (Eds.). Nanobiomaterials in Clinical Dentistry. ( $1^{\text {st }}$ edn.). Elsevier, Amsterdam, Netherlands, Europe.

18. Peters OA, Peters CI, Schonenberger K, Barbakow F (2003) Pro Taper rotary root canal preparation: effects of canal anatomy on final shape analysed by micro CT. Int Endod J 36(2): 86-92.

19. Gomes-filho JE, Silva FO, Watanabe S, Cintra LT, Tendoro KV, et al. (2010) Tissue reaction to silver nanoparticles dispersion as an alternative irrigating solution. J Endod 36(10): 1698-1702.

20. Wu MK, Wesselink PR (1993) Endodontic leakage studies reconsidered. Part I. Methodology, application and relevance. Int Endod J 26(1): 37-43. 
21. Grossman LI, Oliet S, Carlos E, Rio D (1988) Endodontic practice, Philadelphia, Lea \& Febiger

22. Kesler Shvero D, Abramovitz I, Zaltsman N, Perez Davidi M, Weiss EI, et al. (2013) Towards antibacterial endodontic sealers using quaternary ammonium nanoparticles. Int Endod J 46(8): 747-754.
23. Meechan JG (2000) Intra-oral topical anaesthetics: a review. J Dent 28(1): 3-14.

24. Schafer E (2002) Effect of physical vapor deposition on cutting efficiency of nickel-titanium files. J Endod 28(12): 800-802. 